\title{
Recruitment, growth and survival of Lessonia nigrescens (Phaeophyta) at various tidal levels in exposed habitats of central Chile
}

\author{
B. Santelices and F. P. Ojeda* \\ Departamento de Biología Ambiental y de Poblaciones, Facultad de Ciencias Biológicas, Pontificia Universidad Católica de \\ Chile, Casilla 114-D, Santiago, Chile
}

\begin{abstract}
Mortality effects of ecological factors have generally not been tested in field population studies of benthic algae. We first measured recruitment, growth and survival of the low-intertidal/ shallow-subtidal Lessonia nigrescens at 4 tidal levels in exposed rocky habitats in central Chile. Through experimental manipulation we have evaluated the effects of the abiotic environment, smallsize grazers and mid-littoral algae on the survival of the juveniles of L. nigrescens recruited in the upper part of its vertical range. Disturbance effects of adult plants and grazing effects of large-sized subtidal herbivores on juvenile recruitment, and effects of interspecific interference on the survival of newly settled juveniles were also evaluated. Interference by adult plants and grazing by large-sized subtidal herbivores completely inhibit recruitment. In their absence, the abiotic environment limits recruitment and growth of $L$. nigrescens at the uppermost tidal level while inter-specific interference owing to over-shading by the fastest growing individuals limits the lower-most extent of the belt. Interference by adult plants and grazing are patchy and often mutually exclusive in the field Recruitment within the band of $L$. nigrescens is maximal in patchy vegetational openings which are large enough to experience reduced disturbance by adult plants and small enough for reduced grazing pressure. In mature, consolidated belts of $L$. nigrescens on vertical walls these openings correspond to roughly triangular areas with the hypothenuse formed by interholdfast distances of 1 to $2 \mathrm{~m}$. Such patchy vegetational openings can be produced normally by dislodgement of old, eroded plants.
\end{abstract}

\section{INTRODUCTION}

Many ecological factors affect algal spore germination and growth under laboratory conditions (see reviews by Lüning, 1981; Norton et al., 1981; Round, 1981; Russell and Fielding, 1981; Vadas and Norton, 1982). However, the mortality effects of these factors have generally not been tested in field population studies of benthic algae. Chapman (1979) and Vadas (1979) remarked on the general absence of population studies with seaweeds; exceptions are Rosenthal et al. (1974), Hay (1979) and Chapman and Goudey (1982).

Grazing and interference by adult plants are among the 2 most important ecological factors controlling recruitment of kelp species in the field; see reviews by Lawrence (1975) and Lubchenco and Gaines (1981) on grazing, and the studies by Dayton $(1971,1975)$, Sousa

\footnotetext{
- Present address: Departments of Botany and Zoology, University of Maine, Orono, Maine 04469, USA
}

(1979), Santelices et al. (1980) and Kastendiek (1982) for inter-specific interference by adult plants. However, both factors seem to be patchy and often mutually exclusive in the field. In central Chile, barren areas with dense aggregations of the black sea urchin $\mathrm{Te}$ trapygus niger Molina are especially common in intertidal-subtidal pools with frequent water exchange but not directly exposed to wave action. The opposite seems to be true for adult individuals of Lessonia nigrescens Bory. Frond movements resulting from water motion can restrict populations of sea urchins away from the kelps, especially during low tides. Recruitment of juveniles of $L$. nigrescens, therefore, could be expected to occur in areas where these 2 factors counteract each other. This situation would correspond to vegetational openings small enough to have reduced grazing pressure and large enough to have reduced disturbance by adult plants. In this study we first measured recruitment, growth and survival of the low intertidal-shallow subtidal $L$. nigrescens at 4 
tidal levels in exposed rocky habitats in central Chile. We have experimentally evaluated effects of abiotic environment, small-size grazers and mid-littoral algae on survival of juvenile $L$. nigrescens recruited in the upper part of its vertical range. Disturbance effects of adult plants and grazing effects of large-sized subtidal herbivores on juvenile recruitment in the belt, and effects of interspecific interference on survival of newly settled juveniles was also evaluated. We then searched in the field for an optimum size of vegetational discontinuity likely to result in increased juvenile recruitment.

\section{MATERIALS AND METHODS}

\section{Study site}

The study was conducted in the vicinity of Caleta Los Molles $\left(32^{\circ} 15^{\prime} \mathrm{N} ; 71^{\circ} 30^{\prime} \mathrm{W}\right)$ in central Chile. Details of zonation pattern and species distribution in exposed rocky habitats in this area have been described previously (Santelices et al., 1980, 1981; Ojeda and Santelices, 1984). In this area the kelp Lessonia nigrescens forms an intertidal-shallow subtidal vegetational belt 3 to $4 \mathrm{~m}$ wide. Extended flat colonies of the crustose, non-calcareous Codium dimorphum Svedelius and densely packed, cushionlike aggregations of Gelidium chilense Santelices et Montalva occupy the $1 \mathrm{~m}$ zone immediately above the kelp. Expansive, pink colonies of the crustose coralline Mesophyllum sp. extend downward to 4 to $5 \mathrm{~m}$ from the level of the holdfast of $L$. nigrescens.

\section{Experimental treatments}

Nine experimental plots of various sizes were established along $25 \mathrm{~m}$ of rocky walls (Fig. 1). In Jul 1981, all individuals of Lessonia nigrescens were removed from 8 plots. Adult plants of $L$. nigrescens were maintained in Plot 3 to evaluate the effects of adult individuals on juvenile recruitment.

Four plots $(6,7,8,9)$ were used to study single or interacting effects of middle intertidal grazers and algae on the recruitment of Lessonia nigrescens (Fig. 1). All grazers noted - mainly Collisella araucana (Orbigny), C. ceciliana (Orbigny), Siphonaria lessonii Blainville, Tegula atra (Lesson) and Chiton granosus Frembly - were removed from Plots 8 and 9 and allowed to remain in Plots 6 and 7. A $2 \mathrm{~m}$ long, $0.3 \mathrm{~m}$ high metallic fence running from the upper-intertidal to the shallow subtidal zone was cemented between Plots 7 and 8. Mid-littoral intertidal algae (mostly Codium dimorphum and Gelidium chilense) were removed from Plots 7 and 8 .

Two other plots, 4 and 5, were used to evaluate the interacting effects of large-sized subtidal and smallsized, middle intertidal grazers on Lessonia nigrescens recruitment. A $1.5 \mathrm{~m}$ high vertical wall was built up in the channel separating the subtidal portions of Plots 4 and 5 from all others (Fig. 1). Two hundred individuals of the common black sea urchin Tetrapygus niger of 5 to $10 \mathrm{~cm}$ test diameter were added to a pool between the Plots 4 and 5. Mid intertidal grazers were removed from Plot 4 but allowed to remain in Plot 5.

Two plots (1 and 2) were used to measure effects of intra-specific interference on growth and mortality

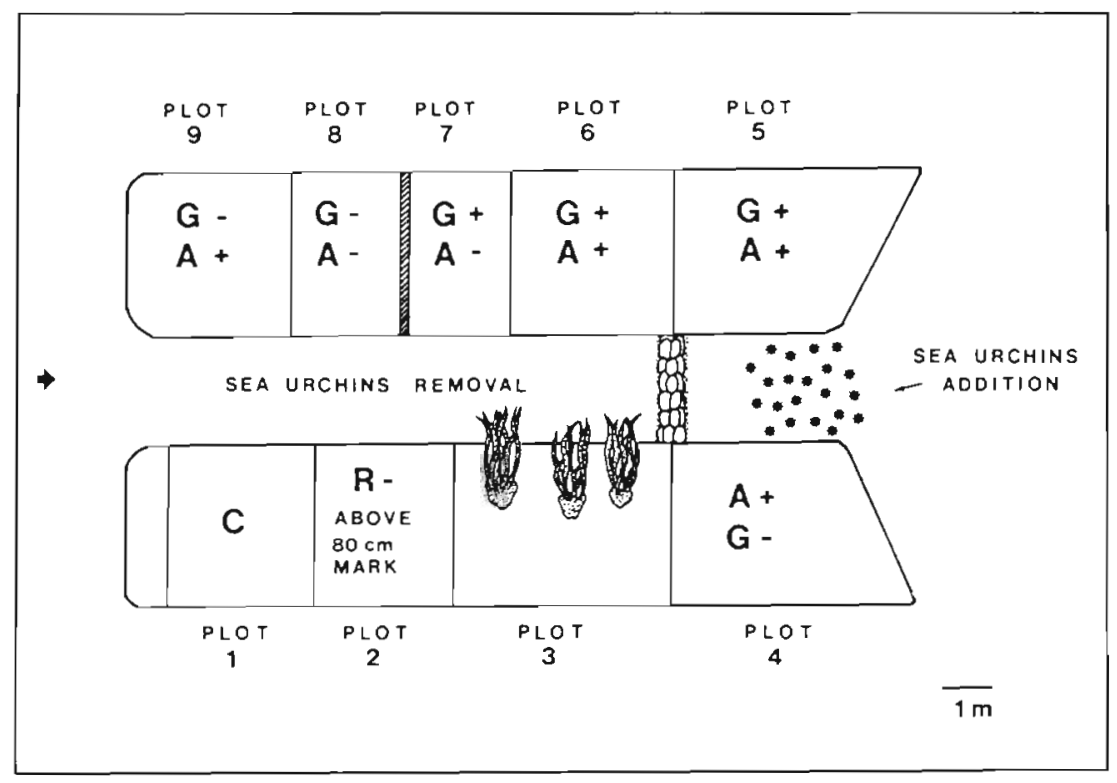

Fig. 1. Diagram of study site showing distribution of experimental plots. G: grazers; A: middle intertidal algae; R: removal of juveniles recruited above $80 \mathrm{~cm}$ mark; C: control; + : presence; - : absence through removal 
rates of settled juveniles. All individuals of Lessonia nigrescens settled in the upper half of Plot 2 were removed in Aug 1981, 1 mo after the first appearance of the juvenile $L$, nigrescens. The effects of such removals on the growth and mortality rates of the individuals settled in the lowermost half of the plots were compared with equivalent measurements made in Plot 1.

Each experimental plot was monitored monthly from Jul 1981 to Oct 1982. This included counting the number of individuals of Lessonia nigrescens at each experimental plot and measuring the longest frond on 50 randomly chosen plants in each plot. For density determinations 2 sizes of quadrats were used. While individuals of $L$. nigrescens were small and dense (up to Dec, 1981), five $25 \times 25 \mathrm{~cm}^{2}$ square quadrats were randomly placed in each experimental plot. When the plants reached sizes exceeding $50 \mathrm{~cm}$ in length (up to Apr 1982), five $0.25 \mathrm{~m}^{2}$ square quadrats were used. In Apr 1982 the initial plant density in each experimental plot was very reduced. Thereafter, each plant found in the plots was enumerated and measured.

To perform the above measurements, 3 vertical levels were initially established within the band of newly settled individuals of Lessonia nigrescens in each plot (Fig. 2). The first included the uppermost 50

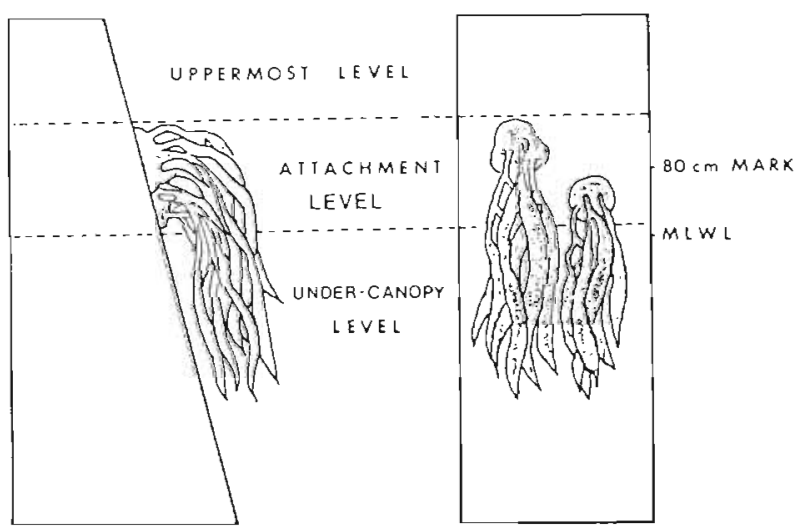

Fig. 2. Lessonia nigrescens. Vertical areas considered in this study

to $80 \mathrm{~cm}$ of the band and corresponded to the individuals settled in a level normally not occupied by adult $L$. nigrescens in consolidated belts. This was named the uppermost level. The second level included the 100 to $150 \mathrm{~cm}$ zone below and corresponded to the vertical elevation normally occupied by the holdfasts of $L$. nigrescens; we named it attachment level. The third level corresponded to the zone receiving the shade of the fronds of $L$. nigrescens and was recognized as the under-canopy level. A pink crust of Mesophyllum sp. is normally found at this level in undisturbed (preremoval) conditions. In Plots 1 and 2, measurements of plant recruitment, growth and survivorship were made separately in the upper and lower vertical halves of the attachment level. The limit was set at about $80 \mathrm{~cm}$ above mean low water level (MLWL) and will be referred to as the $80 \mathrm{~cm}$ mark.

Monthly monitoring also included removal of grazers wherever pertinent, replacement or enforcement of the barriers limiting grazers motility and measurements of several environmental parameters (irradiance using a Li-cor Model LI-185 quantum meter and temperature) at selected times.

An additional and final monitoring of all plots was performed on May 1983, 6 mo after the last regular control (Oct 1982) to evaluate changes in growth and mortality rates of Lessonia nigrescens. No removal of grazers was performed between Oct 1982 and May 1983.

A field search for size of vegetational openings, optimal for juvenile recruitment was conducted during Aug and Sep 1982. This optimal patch size was estimated by direct measurements of interholdfast distances, as related to the number of juveniles settled in the interholdfast area.

\section{RESULTS}

\section{Recruitment and growth in absence of grazers and algae (Plot 8)}

Juvenile Lessonia nigrescens first appeared in Aug 1981 ; by Sep they had attained a size large enough (ca. $5 \mathrm{~cm}$ long) to be measured in the field. The recruitment formed a vertical $2 \mathrm{~m}$ wide band extending downward from about $1.3 \mathrm{~m}$ above MLWL. Recruitment densities in Sep 1981 ranged from 6,000 to 8,000 individuals $\mathrm{m}^{-2}$ in the attachment and under canopy areas and notoriously fewer (ca. 2,500 ) in the uppermost level of the $L$. nigrescens belt (Fig. 3).

Survival and growth rates were different at the 3 levels studied (Fig. 3). Survival and growth were lowest at the uppermost intertidal levels of recruitment. Densities of 2,500 to 3,000 individuals $\mathrm{m}^{-2}$ measured in Sep 1981 decreased to about 160 a month later and to 20 to 30 by Dec. By Feb 1982, most of the individuals recruited at this level had disappeared. Scattered dwarf individuals could be found at this tidal level in rocky areas with surface irregularities which retain variable amounts of water during low tides.

Mortality rates were lowest and growth rate highest among individuals settled at the attachment level. For the following 21 mo after recruitment there was a con- 

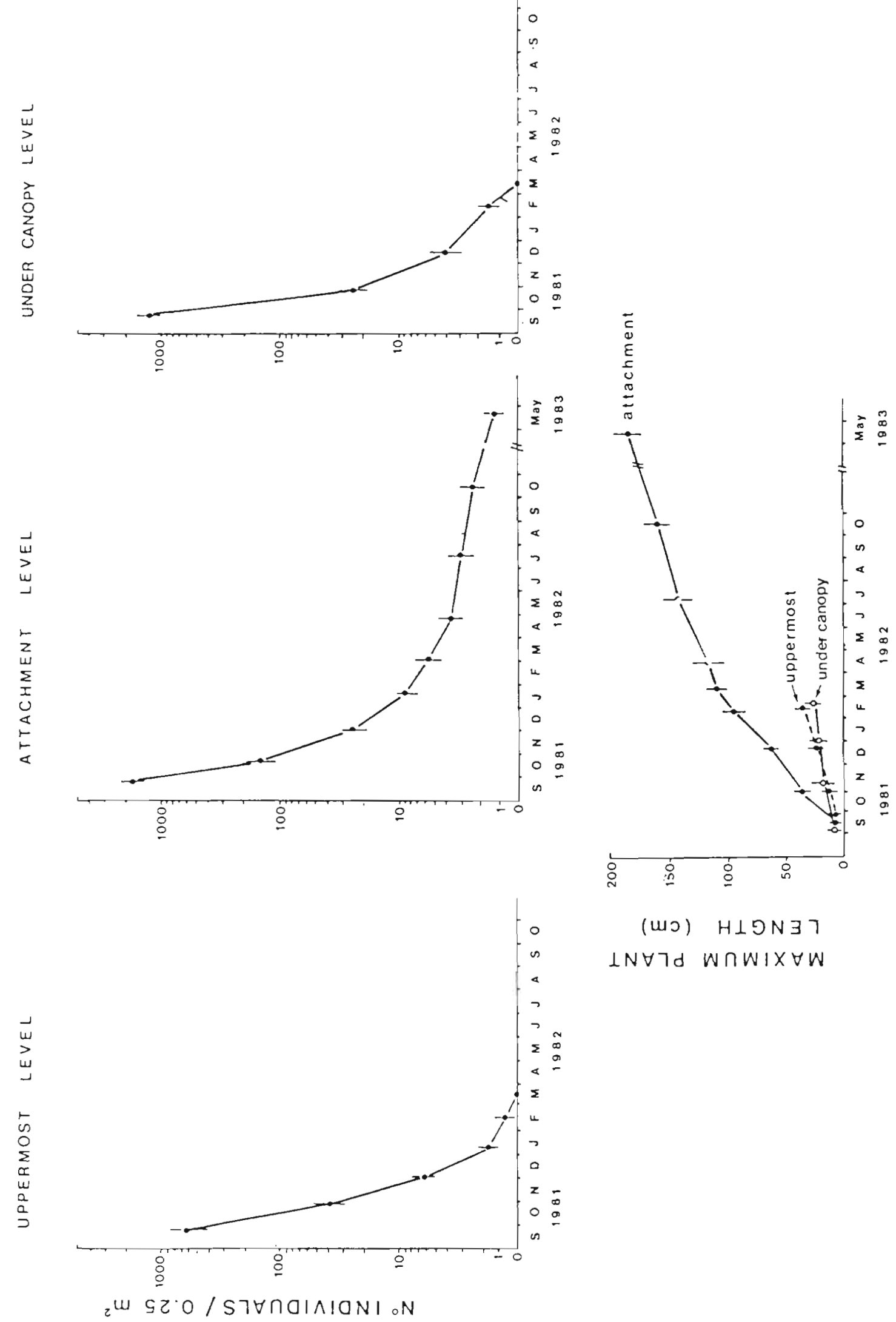
tinuous reduction in plant densities and a continuous increase in frond length. By May 1983 initial densities of 6,000 and 8,000 ind $\mathrm{m}^{-2}$ had decreased to 4 to 6 ind $\mathrm{m}^{-2}$; frond length had increased from about $5 \mathrm{~cm}$ in Sep 1981 to $175 \pm 15 \mathrm{~cm}$ by May 1983.

Average survival values and growth rates of the individuals settled in the under-canopy level were low (Fig. 3). In this case, however, mortality seemed to be a function of the shade produced by the fast growing individuals which settled at the level immediately above. Twenty photon-flux densities measurements performed during periods of low tide on 3 consecutive days during Oct, Nov and Dec 1981, indicated that the growing canopy of the 50 to $70 \mathrm{~cm}$ long individuals settled at the attachment level could reduce to 40 to $50 \%$ the incident light. A dense canopy of $2 \mathrm{~m}$ long individuals of Lessonia nigrescens could further reduce these values to less than $10 \%$. Therefore, the light intensity reaching the individuals settled in the under-canopy level is significantly reduced as compared to these in the attachment level. In Mar 1982, all individuals settled at the under-canopy level have disappeared.

\section{Recruitment and growth in the absence of uppermost intertidal individuals of Lessonia nigrescens (Plots 1 and 2)}

Recruitment, growth and mortality rates of juvenile Lessonia nigrescens at the 3 tidal levels in Plots 1 and 2 were essentially similar to those already described for Plot 8. In Plot 1, growth and mortality rates of the individuals settled above and below the $80 \mathrm{~cm}$ mark within the attachment level were measured separately (Fig. 4). Individuals settled below the $80 \mathrm{~cm}$ mark had decreased growth rates and increased mortality as compared with those occurring immediately above. Holdfast overgrowth and dislodgement by wave impact of dwarf individuals beneath the frond of fast growing thalli were observed in the field, especially among the plants settled in the lower half of the attachment level. Owing to the higher mortality rate of these individuals and to the faster growth of the uppermost individuals, there was a gradual replacement of slowgrowing lower plants by fast-growing upper individuals. Thus, a majority of the 12 to 15 individuals $\mathrm{m}^{-2}$ found in the belt 15 mo after recruitment seems to correspond to individuals settled above and around the $80 \mathrm{~cm}$ mark. As the replacement of the individuals is a gradual phenomenon, the width of the attachment level of the belt did not change significantly during the $15 \mathrm{mo}$.

When the thalli settled in the lowermost half of the attachment level were allowed to grow without the shade of the uppermost individuals (Plot 2), survival and growth rates were increased, approaching the values shown by individuals settled in the upper half of Plot 1 (Fig. 4). In Plot 2 a downward extension of the lower limit of the belt owing to increased survival of the lowermost individuals was expected but not observed. The mature belt of Lessonia nigrescens in Plot 2 had a vertical extent essentially similar to that in the Plot 1 . Seemingly, growth of the uppermost individuals in Plot 2 (those settled immediately below the $80 \mathrm{~cm}$ mark) limited the survival of thalli settled farther below.

\section{Recruitment and growth in presence of small-sized middle intertidal grazers and algae (Plots 6, 7 and 9)}

The presence of small-sized, middle intertidal grazers and of the algae Codium dimorphum and Gelidium chilense above the normal upper limit of the mature, consolidated belt of Lessonia nigrescens had no effect on recruitment, growth and survival of the upper individuals of Lessonia nigrescens (Fig. 5). Growth and survival rates of the individuals settled at the 2 other levels (attachment and under-canopy) were essentially similar to those already described for Plot 8.

It is interesting to note that one individual of Lessonia nigrescens survived in the uppermost level of Plot 9. This corresponded to a plant settled in a rocky depression that retained water during low tides. Maximum frond length attained by this plant by Oct 1982 was 97 to $105 \mathrm{~cm}$. This value is $75 \%$ less than the mean size of thalli of $L$. nigrescens growing at the attachment level in Plot 8 . This plant had disappeared by May 1983.

\section{Recruitment and growth in presence of adult plants (Plot 3)}

No recruitment of juveniles of Lessonia nigrescens was observed in the plot with adult plants.

\section{Recruitment in presence of large, subtidal grazers (Plots 4 and 5)}

No recruitment of Lessonia nigrescens occurred during the first $12 \mathrm{mo}$ in plots where sea urchins were added. In Aug 1982, 2 juveniles of L. nigrescens settled high in the attachment area, reaching lengths of 45 and $50 \mathrm{~cm}$ by Oct 1982 . These plants had disappeared by May 1983. 


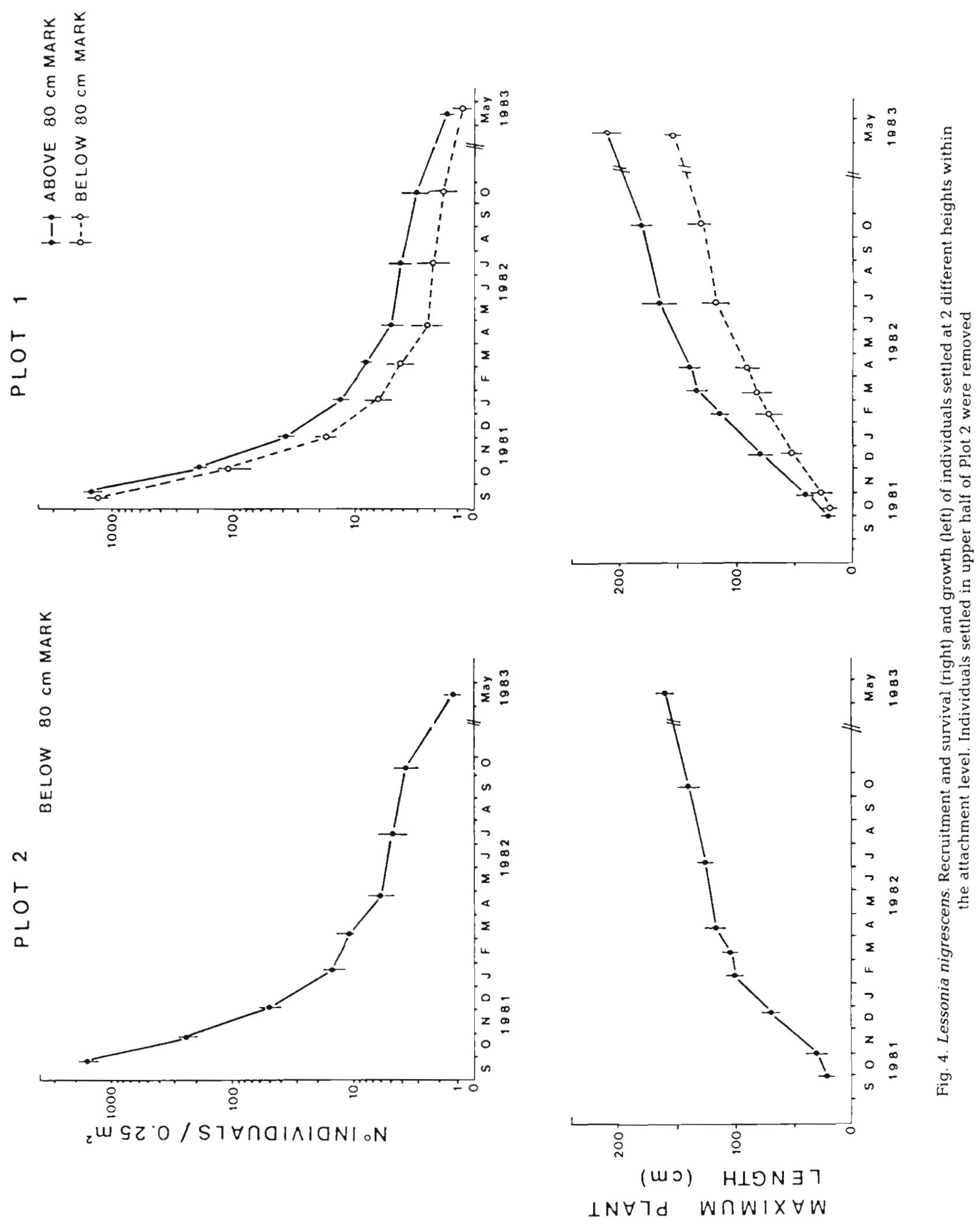



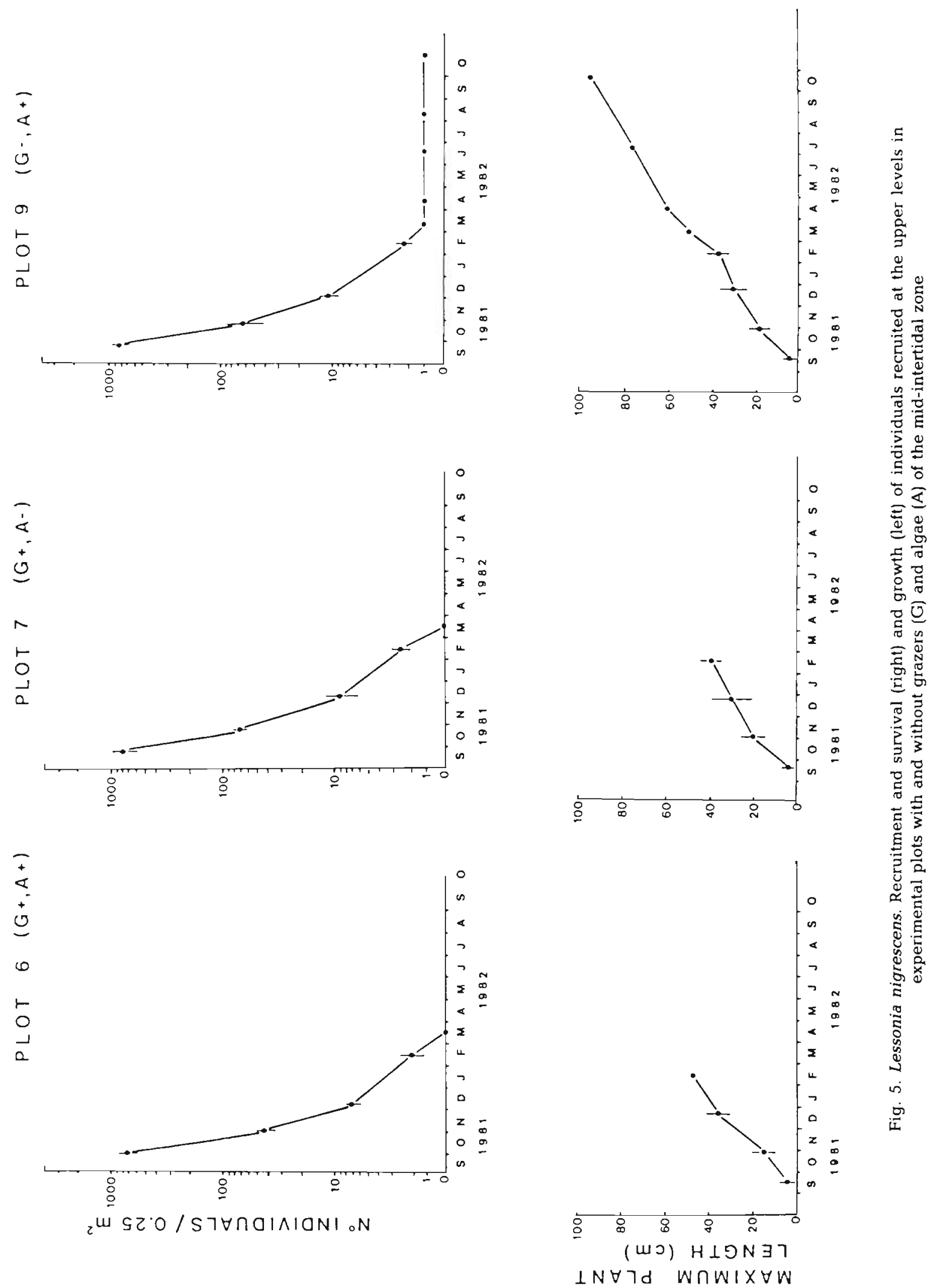


\section{Recruitment in relation to size of vegetational openings}

Field measurements in search for optimum size of vegetational opening for juvenile recruitment are shown in Fig. 6. Maximum recruitment corresponds to vegetational discontinuities of 1.0 to $2.0 \mathrm{~m}$ of interholdfast distance. Although fronds of mature plants of Lessonia nigrescens are normally longer than values of interplant distance, water moves only the distal portion of the fronds, especially during low tides (Fig. 6). In addition, the frond of 2 plants contiguous to a vegetational opening are moved simultaneously in one or another direction by wave action wiping out intruding grazers (Fig. 6). As a result, there is a roughly triangular area with the hypothenuse formed by the interplant distance which is inaccessible to grazers during most of a tidal period. It is difficult to calculate exactly the size of the undisturbed triangular area allowing increased juvenile recruitment in the field. Observations indicate that it is a function of total frond length, degree of rocky slope, length of tidal period, and density and motility of grazers. Field observations also indicate that frond movements could limit grazer incursions from the subtidal during low tides only. Sea urchins and other grazers can reach these areas during high tides when the fronds of L. nigrescens spread almost perpendicularly with respect to the substratum and stop rubbing against the rocky surface.

\section{DISCUSSION}

Interference by adult Lessonia nigrescens and grazing completely inhibit recruitment of this species. In the absence of these disturbance factors, the kelp recruited in a vertical range much greater than that normally occupied by the mature, consolidated belt. Owing to the effects of several ecological factors, the belt originally recruited becomes restricted in its vertical extent within 7 mo after recruitment.

In the absence of grazing and adult plant, recruitment, growth and survival rates of Lessonia nigrescens, as well as mortality factors affecting survival,
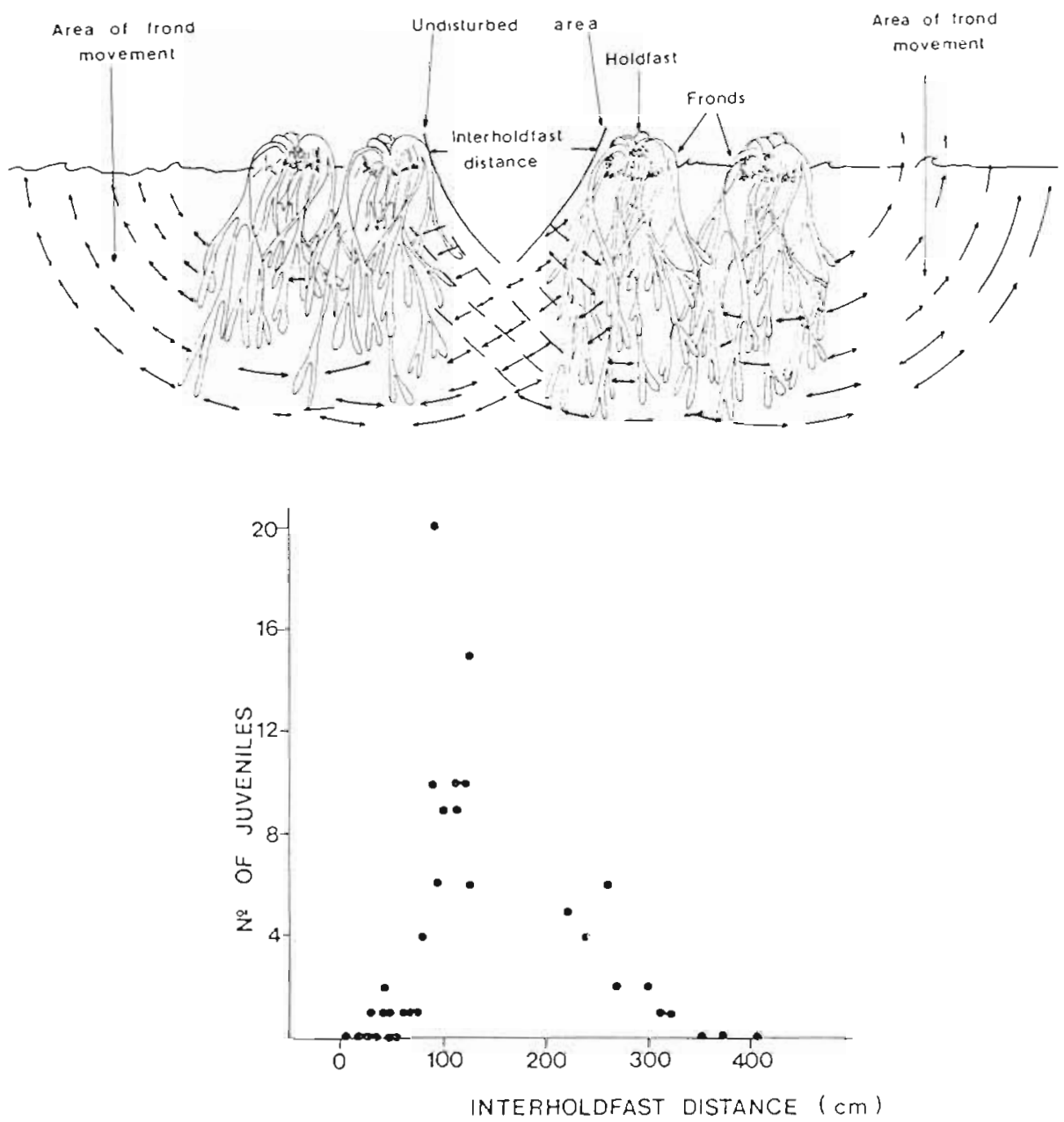

Fig. 6. Lessonia nigrescens. Number of juveniles as a function of interholdfast distance. Diagram represents a vegetational opening within the belt. Frond movement by waves produces a recruitment area with reduced grazing pressure and reduced interference by adult fronds 
were different at various tidal levels. Recruitment values were smallest at the uppermost limit of the band. Removal of the middle intertidal algae and grazers did not significantly increase recruitment at this level, nor did it decrease mortality rates. Maximum mortality values for juvenile $L$. nigrescens at this level occurred during spring-summer; this time features an increased frequency of low-tides during day light coupled with increased solar radiation and temperature in central Chile (Guiler, 1959; Santelices et al., 1981). Thus, as frequently found in other temperate latitudes (Connell, 1961, 1972, 1975; Dayton, 1971, 1975; Schonbeck and Norton, 1978; Lubchenco, 1980), the abiotic environment appears to be limiting the upper extent of this species. No evidence was found in this study of interactions between biotic and abiotic factors in limiting the upper extent of $L$. nigrescens as has been described for other intertidal species (Lubchenco and Cubit, 1980; Santelices et al., 1981). However, results in a related study (Ojeda and Santelices, 1984) indicate that dense downward growth of the middle intertidal Gelidium chilense could limit recruitment of L. nigrescens if experimental removal were performed during summer.

In the absence of adult Lessonia nigrescens and large-sized subtidal grazers, intraspecific interference owing to overshading by the fastest growing individuals appears as the most important factor determining the lowermost extent of $L$. nigrescens. Intraspecific interference is known to regulate population structure especially of subtidal kelps (Rosenthal et al., 1971; Santelices and Ojeda, 1984); recently it has been identified as an important mortality factor in the population dynamics of 2 brown algal species (Chapman and Goudey, 1982; Vadas et al., 1982). Yet, infrequently it has been considered an important agent regulating the lower limit of intertidal populations in the field.

Although interference by adult Lessonia nigrescens and grazing was expected to inhibit recruitment of juveniles, it was somewhat surprising that the inhibition effect reached the uppermost levels of recruitment. In the case of grazing this could be explained by sea urchins migrating upwardly during high waters but at this time we have no explanation for the interference by adult plants.

The finding of an optimal vegetational opening, which allows increased recruitment and is within the range of frond size of adult plants, strongly supports the idea that recruitment in the band of Lessonia nigrescens is maximal in areas with both reduced disturbance and grazing pressure. Such patchy vegetational openings can be produced normally by dislodgement of old, eroded plants. Grazers probably exert pressure on these areas, particularly during high water, but likely less than on barren grounds. The net effect of intermittent grazing would be less intraspecific competitive interference by a reduction in the number of juvenile L. nigrescens. It is as yet unknown if a similar phenomenon occurs in populations of other kelp species, but in the vertical intertidal-subtidal bands of $L$. nigrescens this appears as the most probable mechanism allowing permanence of the belt in space and time.

Acknowledgements. The authors appreciate help by Julio Vásquez, Isabel Meneses, Juan Correa and Daniel Moraga in the field work, and economic support by 'Subsecretaría de Pesca, Ministerio de Economía, Fomento y Reconstrucción. Criticisms and comments by P. Dayton, J. Geaghan, F. Jaksić and J. McLachlan are acknowledged with gratitude.

\section{LITERATURE CITED}

Chapman, A. R. O. (1979). Biology of seaweeds. Levels of organization. Edward Arnold Ltd., London

Chapman, A. R. O., Goudey, C. L. (1982). Demographic study of Leathesia difformis in Nova Scotia. Abstracts, First International Phycological Congress, St. John's, Newfoundland, Canada, August 8-14, 1982

Connell, J. H. (1961). The influence of interspecific competition and other factors on the distribution of the barnacle Chthamalus stellatus. Ecology 42: 710-723

Connell, J. H. (1972). Community interaction on marine rocky intertidal shores. A. Rev. Ecol. Syst. 3: 169-192

Connell, J. H. (1975). Some mechanisms producing structure in natural communities. In: Cody, M. L., Diamond, J. M. (ed.) Ecology and evolution of communities. Harvard University Press, Cambridge, Massachusetts, p. 460-490

Dayton, P. K. (1971). Competition, disturbance and community organization: the provision and subsequent utilization of space in a rocky intertidal community. Ecol. Monogr. 41: $351-389$

Dayton, P. K. (1975). Experimental evaluation of ecological dominance in a rocky intertidal community. Ecol. Monogr. 45: $137-159$

Guiler, E. P. (1959). The intertidal ecology of the Montemar area, Chile. Pap. Proc. R. Soc. Tasmania 93: 165-183

Hay, C. (1979). Growth, mortality, longevity and standing crop of Durvillaea antarctica (Phaeophyceae) in New Zealand. In: Proceedings of International Seaweed Symposium 9: 97-104

Kastendiek, J. (1982). Competitor-mediated coexistence: interactions among three species of benthic macroalgae. J. exp. mar. Biol. Ecol. 62: 201-210

Lawrence, J. M. (1975). On the relationship between marine plants and sea urchins. Oceanogr. mar. Biol. A. Rev. 13: 213-286

Lubchenco, J., Cubit, J. (1980). Heteromorphic life histories of certain marine algae as adaptations to variations in herbivory. Ecology 61: 676-687

Lubchenco, J., Gaines, S. D. (1981). A unified approach to marine plant-herbivore interactions. I. Populations and communities. A. Rev. Ecol. Syst. 12: 405-437

Lüning, K. (1981). Light. In: Lobban, C., Wynne, M. J. (ed.) The biology of seaweeds. Botanical monographs, Vol. 17. University of California Press, Berkeley, p. 326-355

Norton, T. A., Mathieson, A. C., Neushul, M. (1981). Morphologies and environment. In: Lobban, C. S., Wynne, M. 
J. (ed.) The biology of seaweeds. Botanical monographs, Vol. 17. University of California Press, Berkeley, p. 421-451

Ojeda, F. P., Santelices, B. (1984). Ecological dominance of Lessonia nigrescens (Phaeophyta) in central Chile. Mar Ecol. Prog. Ser.

Rosenthal, R. J, Clarke, W. D., Dayton, P. K. (1974). Ecology and natural history of a stand of giant kelp, Macrocystis pyrifera, off Corona del Mar, California. Fish. Bull. U.S. 72: $670-684$

Round, F. E. (1981). The ecology of algae. Cambridge University Press, Cambridge

Russell, G., Fielding, A. J. (1981). Individuals, populations and communities. In: Lobban, C. S., Wynne, M. J. (ed.) The biology of seaweeds. Botanical monographs, Vol. 17. University of California Press, Berkeley, p. 393-420

Santelices, B., Castilla, J., Cancino, J., Schmiede, P. (1980). Comparative ecology of Lessonia nigrescens and Durvil laea antarctica (Phaeophyta) in central Chile. Mar. Biol. 59: 119-132

Santelices, B., Montalva, S., Oliger, P. (1981). Competitive algal community organization in exposed intertidal habitats from central Chile. Mar. Ecol. Prog. Ser. 6: 267-276
Santelices, B., Ojeda, F. P. (1984). Population dynamics of coastal forests of Macrocystis pyrifera in Puerto Toro, Isla Navarino, Southern Chile. Mar. Ecol. Prog. Ser. 14: 176-183

Schonbeck, M., Norton, T. A. (1978). Factors controlling the upper limits of fucoid algae on the shore. J. exp. mar. Biol. Ecol. 31: 303-313

Sousa, W P. (1979). Experimental investigations of disturbance and ecological succession in a rocky intertidal algal community. Ecol. Monogr. 49: 227-257

Vadas, R. (1979). Seaweeds: an overview; ecological and economic importance. Experientia 35: 429-432

Vadas, R., Norton, T, A. (1982). Ecology of benthic marine macroalgae: Introduction and bibliography. In: Rosowski, J. R., Parker, B. C. (ed.) Selected papers in phycology. II. Phycological Society of America, Inc., Lawrence, Kansas, p. 549-556

Vadas, R. L., Miller, S. L., Bolis, C. M. (1982). Population of Ascophyllum nodosum: factors influencing recruitment and germlings. Abstracts, First International Phycological Congress, St. John's, Newfoundland, Canada, August $8-14$

This paper was presented by Dr. J. Winter; it was accepted for printing on April 27, 1984 